\title{
Round-Robin Study of a priori Modelling Predictions of The Dalmarnock Fire Test One
}

\author{
Guillermo Rein ${ }^{* 1}$, José L. Torero', Wolfram Jahn?, \\ Jamie Stern-Gottfried ${ }^{2} 1$, Noah L. Ryder ${ }^{3}$, Sylvain Desanghere ${ }^{4}$ \\ Mariano Lázaro 5 , Frederick Mowrer ${ }^{6}$, Andrew Coles ${ }^{7}$, Daniel Joyeux ${ }^{8}$, \\ Daniel Alvear ${ }^{5}$, Jorge A. Capote ${ }^{5}$, Allan Jowsey ${ }^{1,2}$, \\ Cecilia Abecassis-Empis ${ }^{1}$ and Pedro Reszka ${ }^{7}$
}

1 BRE Centre for Fire Safety Engineering, University of Edinburgh, Scotland, UK 2 Arup, London, UK

3 Packer Engineering Inc, Chicago, USA

4 CTICM, Paris, France

5 GIDAl, Universidad de Cantabria, Santander, Spain

6 Dept. of Fire Protection Engineering, University of Maryland, USA

7 Arup, San Francisco, USA

8 Efectis, Paris, France

\begin{abstract}
An international study of fire modelling was conducted prior to the Dalmarnock Fire Test One in order to assess the state-of-the-art of fire simulations using a round-robin approach. This test forms part of the Dalmarnock Fire Tests, a series of experiments conducted in 2006 in a high-rise building. The philosophy behind the tests was to provide measurements in a realistic fire scenario involving multiple fuel packages and non-trivial fire growth, and with an instrumentation density suitable for comparison with computational fluid dynamics models. Each of the seven round-robin teams independently simulated the test scenario a priori using a common detailed description of the compartment geometry, fuel packages, ignition source and ventilation conditions. The aim of the exercise was to forecast the fire development as accurately as possible and compare the results. The aim was not to provide an engineering analysis with conservative assumptions or safety factors. Comparison of the modelling results shows a large scatter and considerable disparity among the predictions, and between predictions and experimental measurements. The scatter of the simulations is much larger than the error and variability expected in the experiments. The study emphasises on the inherent difficulty of modelling fire dynamics in complex fire scenarios like Dalmarnock, and shows that the accuracy to predict fire growth (i.e. evolution of the heat released rate) is, in general, poor.
\end{abstract}

Keywords: fire modelling; blind; forecast; CFD; FDS; validation

\footnotetext{
* Corresponding author: G.Rein@ed.ac.uk

* Now working at CSTB France
} 


\section{Introduction}

Fire modelling is frequently used in current fire safety engineering practice but discussions have been ongoing for many years now about the accuracy and reliability of the process.

Computer fire modelling was first developed as a research tool in the 1970's (Emmons 1978) after the surge of computer resources. It reached its first applications to real fire engineering problems in the late 1980's (Cox et al. 1989, Cox 1998) and now is widely used (Novozhilov 2001, Cox and Kumar 2002) in many aspects of fire science and engineering. Its current applications range from forensic investigation to risk assessments, life safety, smoke movement and detection, sprinkler performance, structural behaviour, and design of fire safety. Modelling is being used to study fire dynamics in enclosures and to simulate flames, plumes, hot layers and smoke movement during every stage of the fire development, from ignition and flame spread to, and through, flashover and extinction.

Modelling is among the fastest developing areas in fire safety science. However, its ability to reproduce fire phenomena lags experimental understanding by about 10 years (McGrattan 2005). Several papers and standards addressing the verification and validation of fire models have been published recently (ASTM 2005, NUREG 2007, Salley et al. 2007, Wen et al. 2007) and many more are expected. In general, these aim at determining the level of accuracy and the range of applicability of given fire models by means of comparison to experiments.

The large majority of the studies that have compared simulations to experiments have found them in reasonable agreement. These studies show that current modelling provides good predictions of the average thermal effects of a fire (e.g. hot layer temperature) but do not address the accuracy of the predictions of the fire development (e.g. fire growth and/or the heat released rate) or spatial resolution. In the great majority of cases, the simulations have been conducted after the tests and with good access to the recorded experimental data (this is known as a posteriori modelling). Thus, the comparisons are not blind and the modelling may include some bias due to prior knowledge of the evolution of the event being modelled. This bias may or may not be explicitly reported along the modelling results. Only a few a priori prediction studies are available in the literature (Hakkarainen et al. 1999, Miles et al. 2000, Reneke et al. 2001). These studies were conducted for very simple fire scenarios, that did not include realistic features such as multiple fuel packages, flame spread, window breakage, nontrivial geometry, and the fire source (heat released rate or mass loss rate of the fuel) was provided. However, fire modelling is used in practice to study scenarios that include several of these features and where the fire source is unknown. Of the studies conducted to date, only a few compare modelling results with experimental data from realistic fire scenarios (Reneke et al. 2001, Pope and Bailey 2006), however none of these were conducted a priori or as blind simulations.

The validation of fire models is an essential task for the advancement of fire safety engineering. One of the issues that remain to be further explored is the evaluation of the entire process of fire modelling, in which the mathematical model is only a component. The assumptions made by the user, the collection of data for input and the selection of the parameter values (some available in the literature and from experiments, some not) are crucial components leading to the creation of the input file. Furthermore, the interpretation, claimed 
accuracy and implementation of the model output are key components that further highlight the important roll of the user in the interaction with the model.

It is reasonable to consider that the current state-of-the-art of fire modelling is reflected not only in the mathematical models' capabilities, but also on how fire dynamics is implemented throughout the different stages of modelling. Thus, in order to assess the strengths and limitations of the process as a whole, all the stages of fire modelling need to be investigated both independently and as a whole. This study looks at the overall process but does not underestimate the value of analysing the individual components.

The objective of this study is to compare the modelling results produced a priori by different teams of modellers of a realistic fire scenario, the Dalmarnock Fire Test One. Test One is part of the Dalmarnock Fire Tests series of fire experiments (Abecassis Empis et al. 2007, Rein et al. 2007), conducted in 2006 in a real high-rise building. The study provides a range of forecasted behaviours and a sense of the robustness, consistency and sensitivity of current fire modelling including the predictions of fire growth. The results are compared to the experimental measurements to allow evaluation of the accuracy and reliability of the a priori process as a whole.

\section{Round-Robin Studies in Fire Science}

A round-robin study involves the analysis of a common scenario by several independent teams and then draws conclusions from the comparison of all results (Beard 2000). In fire safety science the most renowned round-robin study was that conducted by Emmons (1968) after his trip around the world visiting 40 fire laboratories in order to compare the different flammability ratings of the same set of common materials. The results showed a large discrepancy and made a case for the critical need of fundamental understanding of flammability tests. The publication of his results prompted the international standardisation of material fire testing. A more recent round-robin study (Pitts et al. 2006) found good agreement between the calibrations of heat flux gauges performed by different fire laboratories, thus reinforcing the reliability of these calibrations.

A round-robin of modelling results typically involves the production of independent predictions of a common event. Conclusions are then drawn from the comparison of the different predictions and the real behaviour. ASTM E 1355 (2005) defines three types of simulation: blind, open and specified. In blind simulations, also called a priori, the modeller is provided only the description of the initial scenario and is responsible for developing the appropriate input from this description, including details of the geometry, material properties, fire development, etc. The modeller has no access to the experimental measurements of the event and thus is providing a forecast. Most fire model validations are open simulations, also called a posteriori, where the modeller is also provided with the results from the experiment. Only a priori simulations are free of the bias that could be introduced by prior knowledge of the development of the event. In specified simulations the modeller is directly given the input file to be run in the model. 
In fire modelling, only a few round-robins can be found in the literature (Beard 2000, Beard 2005). CIB organised and conducted a large and international blind round-robin for fire models (Hakkarainen et al. 1999) but the results were not made publicly available. Only one team published their results independently (Miles et al. 2000). However, the essential objective of a round-robin is to present all the results together for an unbiased comparison. Presenting only a few selected cases can provide a distorted view of the results. The validation exercise published in NUREG (2007) could be viewed as a round-robin study; however it was conducted as an open exercise with access to the experimental results. Very recently, a new blind modelling round-robin was conducted to simulate a fire in a small hotel room (Coppalle et al. 2008). Nevertheless the lack of ample round-robin studies in fire modelling is a pending issue of the discipline.

The present round-robin study involves a pool of participants composed of independent international teams, all working in the field of fire engineering and using fire modelling as part of their professional practice. There are representatives from most branches of fire modelling, from fundamental and applied research to final engineering design. Due to the wide range of participants, the results pertain to a wide range of end-users and allow certain conclusions to be made that reflect on the state-of-the-art of fire modelling. The participants worked independently and had access to a large, common pool of data obtained from the initial conditions prior to the ignition of the fire. Each team submitted one or more simulations that, in their view, represented the best prediction of the process based on their a priori knowledge.

\section{The Dalmarnock Fire Tests}

The large-scale Dalmarnock Fire Tests (Abecassis Empis et al. 2007, Rein et al. 2007) consist of three tests conducted in a 23-storey reinforced concrete building in Glasgow (UK), July 2006. The two tests of main interest here (henceforth referred to as Test One and Test Two) were those conducted in two identical flats, whereas the third test involved only smoke management in a stairwell and will not be further discussed. The Dalmarnock Tests were set up to recreate a realistic fire scenario involving multiple fuel packages arranged in an ordinary fashion, consistent with real dwellings. Arrangements of this type invariably result in fire growth that is not readily obvious and thus prediction of fire development can be a challenge. Nevertheless, the Dalmarnock compartment test was designed to maximise its repeatability. Ignition procedures and fuel distribution were defined in a manner such that potential variations could be kept to a minimum. Furthermore, the comparison of the results from Dalmarnock Fire Test One and Test Two confirms that the repeatability of the tests was high (Rein et al. 2007, Chp 4). This study considers only Test One for comparison against fire modelling, however Test Two is briefly discussed.

\subsection{Description of Test One}

Test One was held in a two-bedroom single family flat, with the living room set up as the main experimental compartment. Test Two was conducted in an identical flat but two floors 
below Test One. An identical fuel arrangement was used in both tests. Both fires grew to flashover conditions but only Test One was allowed to continue burning during post-flashover. A detailed description of the compartments, the fuel layout and the measurements has been given by Abecassis-Empis et al. (2008) and Rein et al. (2007, Chp 2), but an overview is included here for quick reference.

The flat comprised a main corridor off which were two bedrooms, a bathroom and a living room, with a small kitchen off to the side of the living room, as shown in Figure 1. The main experimental compartment was the $3.50 \mathrm{~m}$ by $4.75 \mathrm{~m}, 2.45 \mathrm{~m}$ high living room, with a $2.35 \mathrm{~m}$ by $1.18 \mathrm{~m}$ set of windows (two panes) on the west-facing wall, $1.11 \mathrm{~m}$ above the floor (see Figure 1). It was furnished as a regular living room/office. The general layout was such that most of the fuel was concentrated towards the back corner (NE) of the compartment, away from the window and the doors, with a fairly even fuel loading throughout the rest of the compartment (see Figure 2) and no further loading elsewhere in the flat.

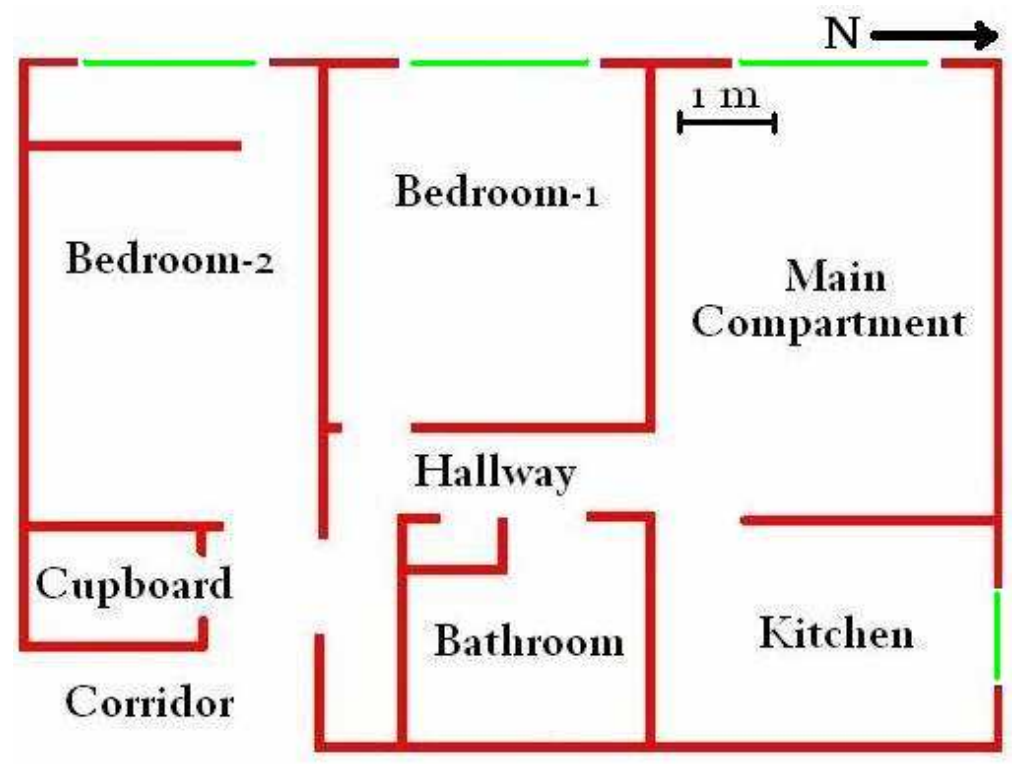

Figure 1: Plan view of the flat layout showing basic dimensions (to scale), rooms and windows [A becassis-Empis et al. (2008) and Rein ef al. (2007)] 


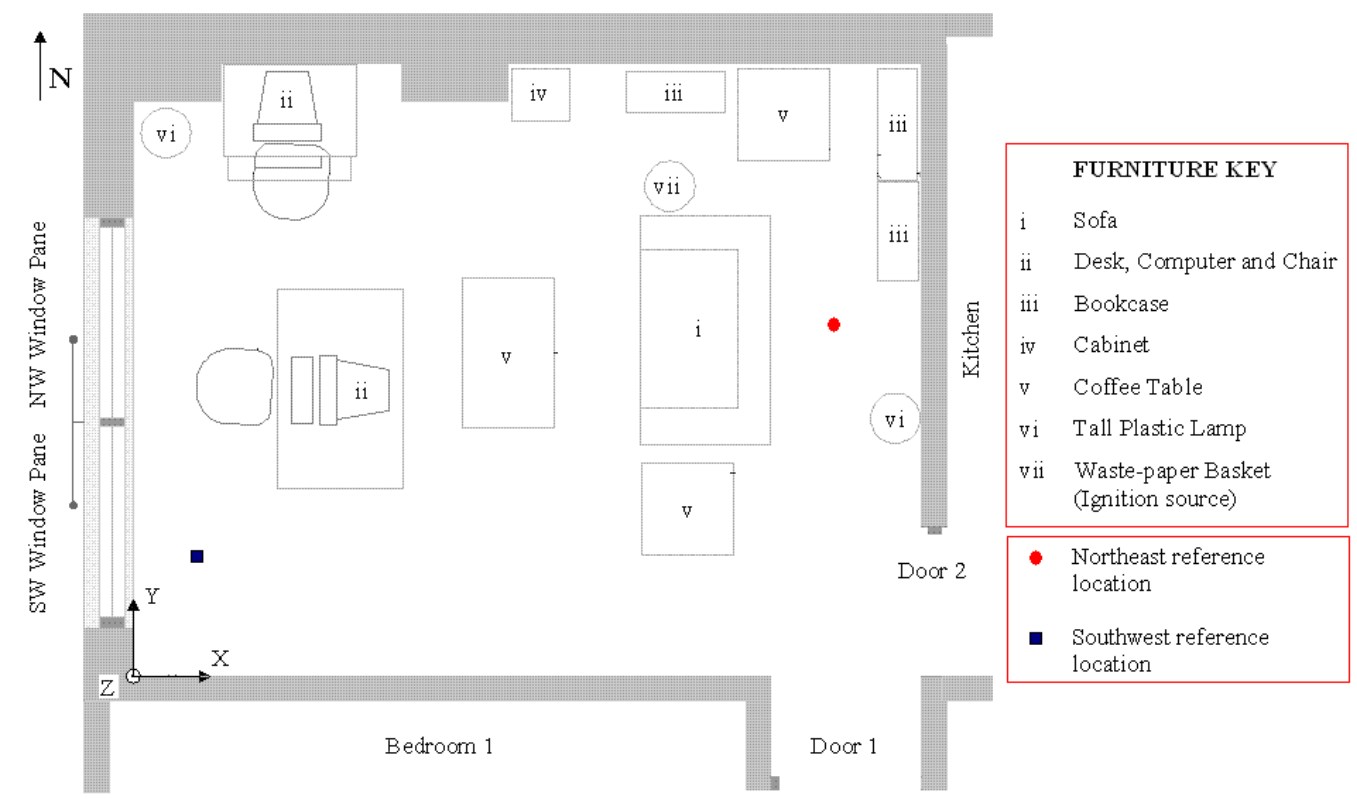

\section{Figure 2: Furniture layout in the main compartment [Abecassis-Empis et al. (2008) and Rein et al. (2007)]}

While the main source of fuel was a two-seat sofa stuffed with retardant flexible polyurethane foam, the compartments also contained two office desks with a computer and a padded chair each, as well as three tall wooden bookcases, a short plastic cabinet, three small wooden coffee tables, a range of paper items and two tall, plastic lamps. The bookcases were fully-laden with books, video tapes, paper-filled cardboard files and several other plastic items, as was the small cabinet. Other minor living room/office items were arranged as they would be in real dwellings. Figure 3a shows a photograph, taken before the test, of the compartment corner where the ignition source, the sofa and nearby items are located. The fuel load density in the main compartment was estimated to be $32 \mathrm{~kg} / \mathrm{m}^{2}$ of wood equivalent, whereas a typical value for office buildings is around $25 \mathrm{~kg} / \mathrm{m}^{2}$ (Milke et al. 2002). The ignition source was a plastic wastepaper basket filled with crumpled newspaper and approximately $500 \mathrm{ml}$ of heptane. It was placed in-between the sofa and a bookcase, directly below a blanket that was draped over the sofa arm. 


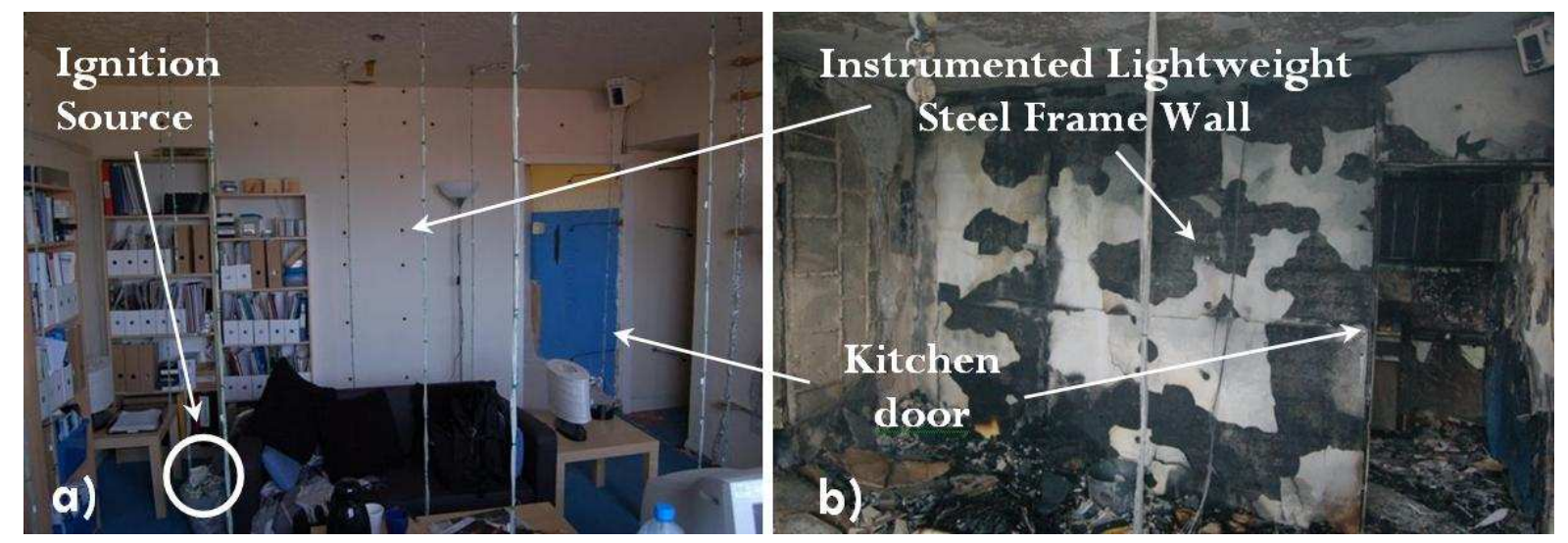

\section{Figure 3: View of the ignition source, the sofa and nearby items in the main compartment: $a$ ) before the fire and $b$ ) after the fire [Abecassis- Empis et al. (2008) and Rein et al. (2007)].}

During Test One all the doors in the flat were left open, except the bathroom and cupboard doors. The front entrance door communicating to the floor access corridor was also left open. Windows of all compartments, excluding the kitchen and bedroom-2, were left closed. The kitchen window was left partially open, creating one vent at the top and another vent at the bottom due to the pivoting mechanism of the pane.

A large number of sensors were installed throughout the flat in order to obtain detailed measurements of the fire development. The instrumentation layout was designed to provide a high density of sensors. More than 270 thermocouples were distributed throughout the main compartment, at different locations and at several heights, to provide gas temperature data at high spatial resolution suitable for comparison with computational fluid dynamics (CFD) simulations. Smoke obscuration was measured using 8 pairs of laser-receiver sensors. Gas velocity was measured at the ventilation openings of the main compartment using 14 bidirectional velocity probes in total. Additionally, more than 15 video cameras, spread throughout the flat, provided visual recordings which allowed monitoring of the fire development. Other measurements include temperatures within and heat fluxes to the east wall (fully instrumented light-steel framing wall) and the ceiling of the main compartment, a dozen smoke detectors in different rooms, and strain and deflection gauges used to monitor the deformation of key structural elements.

The test was initiated by igniting the contents of the wastepaper basket. The fire rapidly spread to the blanket and a few seconds later to the cushions on the sofa. After about $4.5 \mathrm{~min}$ of localised fire on the sofa, the first bookcase ignited, quickly followed by the onset of flashover (5 min after ignition), with sudden reduced visibility and the ignition of most exposed paper items throughout the compartment. The fire continued to burn and broke the kitchen window (glass fell out) 12 min into the test. The north pane of the compartment window was externally forced to break (glass fell out) at $13 \mathrm{~min}$. The other pane fell out due to the fire shortly before $19 \mathrm{~min}$ into the fire. The fire was then put out by the fire brigade after $19 \mathrm{~min}$ of burning. Most of the fuel load was burnt and the majority of the remains were unrecognisable. Figure $3 \mathrm{~b}$ shows a photograph, taken after the test, of the remains at the compartment corner 
where the ignition source, the sofa and nearby items were located. Figure 4 shows the evolution of the average temperature in the main compartment during Test One, where the shaded area indicates standard deviation. A more detailed timeline of the test is described by Abecassis-Empis et al. (2008) and Rein et al. (2007, Chp 3).

Test Two had an identical flat geometry and fuel configuration. The only two significant variations were a smaller amount of heptane used for the ignition protocol and a drastically altered ventilation conditions. The door to the kitchen remained closed for approximately $2 \mathrm{~min}$ after ignition, the door to the corridor for $3 \mathrm{~min}$, and the main door for $4 \mathrm{~min}$. This opening sequence was managed through remote control by an operator and the decisions were taken based on the remote real-time monitoring of the fire development (Rein et al. 2007, Chp 4). The main compartment windows were also opened by remote control, approximately $45 \mathrm{~s}$ after ignition. All other windows of the flat remained fully opened throughout the test. In addition, ventilation conditions in Test Two included a $1.2 \mathrm{~m}$ high $\mathrm{x} 1.4 \mathrm{~m}$ wide hole was previously made in the south wall of the main compartment linking it with bedroom-1 (see Figure 1). The large hole served a double purpose of providing extra ventilation and allowing the test $\mathrm{Crew}^{\dagger}$ an alternative access and evacuation path from the compartment. Despite these drastic differences, the Test Two fire was seen to spread following the same pattern as Test One. Figure 4 juxtaposes the results of Tests One and Two. It can be noted that both tests show an almost identical time to flashover (only $10 \mathrm{~s}$ difference). The difference in the ignition and ventilation conditions between both tests led to a reduction in the average pre-flashover temperature by approximately $50{ }^{\circ} \mathrm{C}$ and to significantly lower spatial scatter. Post-flashover temperatures cannot be compared because fire suppression by fire fighters immediately followed the onset of flashover in Test Two. Although both tests did not produce identical fires the differences are relatively small, and it shows that the Dalmarnock compartment test configuration provided a robust and reasonably repeatable fire scenario for benchmarking.

\footnotetext{
$\dagger$ Two members of the test crew were present in the room during the fire accompanied by Fire Service personnel
} 


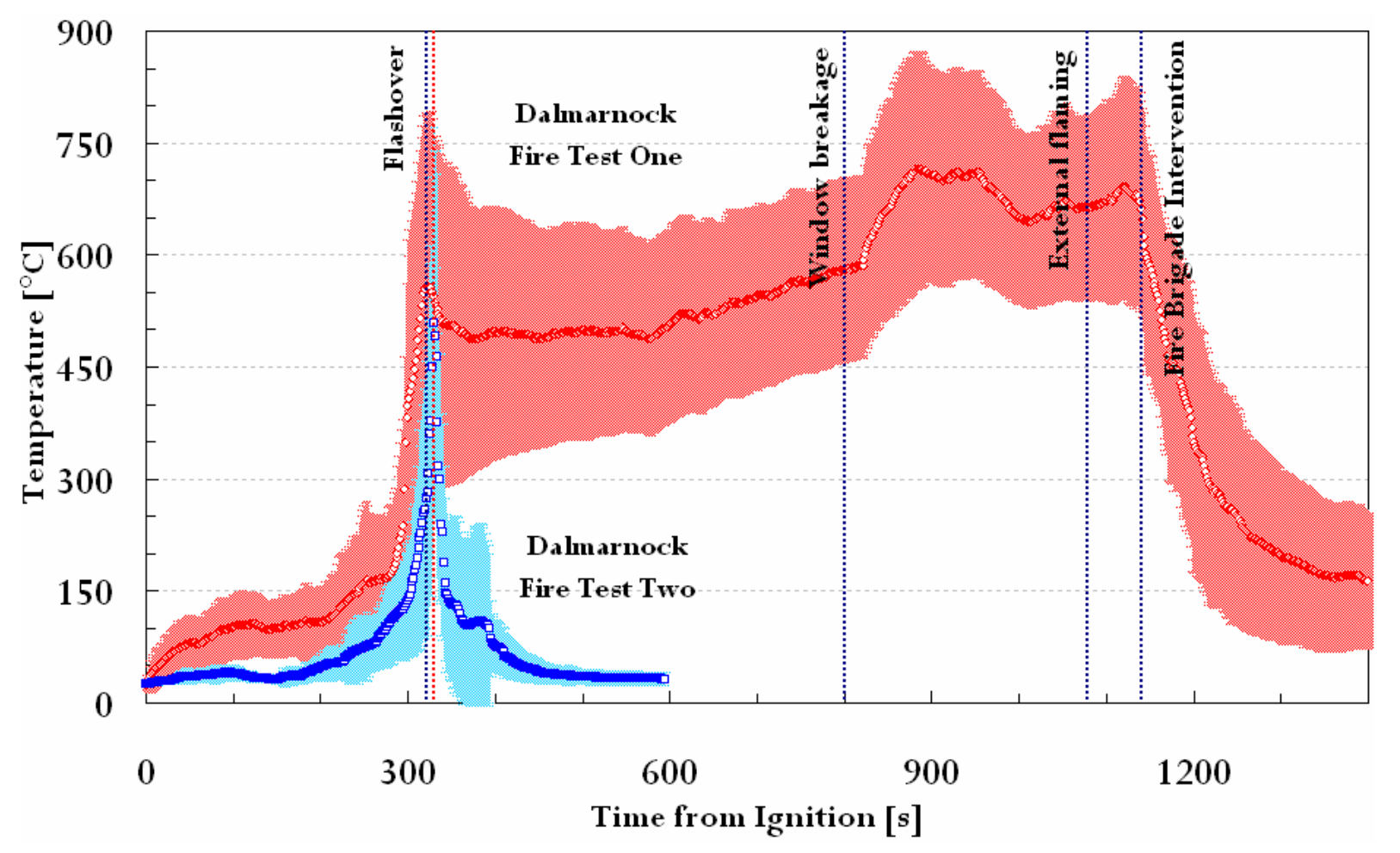

Figure 4: Evolution of the average compartment temperature for Test One and Test Two [Abecassis-Empis et al. (2008) and Rein et al. (2007)]. The shaded areas indicate standard deviation within the compartment. Test One was allowed to continue burning during the post-flashover stages whereas Test Two was extinguished immediately after flashover.

\subsection{The philosophy of the Tests}

It is a common conception that fire experiments could significantly differ from each other when run under the same conditions, and therefore many repeats are necessary to achieve validation data. Given the cost and complexity of large-scale fire tests, it is evident that the number of repeats that will establish statistical validity for the data will never be achieved. This feature distinctive to fire is associated to its inherent complexity and has always cast a shadow of uncertainty upon any modelling validation exercise. Experimental data used for comparison with modelling results can never be considered as robust as it could be in other fields, such as small flames. For example, the Sandia Flames by Barlow et al. (2005) have an excellent reproducibility and count on diagnostics that provide detailed information on temperature, velocities, species and turbulence statistics. These flames have been extensively used to benchmark turbulent combustion models. Such a high level of reproducibility and detailed diagnostics cannot be achieved in large fires, therefore, a different approach was taken in this study.

The philosophy behind the Dalmarnock Fire Tests was to provide instrumentation density suitable for comparison with grids used in CFD simulations and to arrange ignition, fuel and ventilation such as to guarantee a robust test scenario. In order to test this robustness, the fuel layout was defined to minimise variations in the fire spread pattern and identical compartments 
were used in both tests. The two main processes that can lead to drastic differences in fire development are the ignition of individual items before flashover and the windows breaking and falling out. The ignition issue was addressed by defining an ignition protocol for the first item and by placing it in close proximity to a large quantity of fuel arranged vertically, in the form of a bookshelf. This provided an ISO room corner test type of configuration where it is guaranteed that flashover will be attained soon after the ignition of the secondary item. The potential bounds of variability of the data were thus established by using very different ventilation and ignition conditions for both tests. For Test One, only the doors of the main compartment were left open, while for Test Two, all doors and windows were open, ensuring, together with the large opening in the south wall, free flow of air and smoke in and out of the compartment.

Comparison of the data from both experiments establishes that Dalmarnock Test One is a robust and reasonably repeatable fire scenario. The test can therefore be used to assess different aspects of fire safety engineering practice - in this case, fire modelling.

\section{Dalmarnock Round-Robin Study}

The aim of the study was the forecast of fire dynamics for the set scenario. The teams were asked to forecast the test results as accurately as possible, and to avoid an engineering analysis with conservative assumptions or safety factors, as is common for use in fire safety design. All teams were given access to a common pool of information about the test experimental setup and initial conditions $\$$

\subsection{Common Description of the Scenario}

Each team was free to use the information provided as they saw fit according to their own criteria. There were no limitations imposed on the teams for consulting the literature and to search for additional data regarding other fire experiments or similar tests. Any missing information, unclear information or additional details were intended to be complemented by the teams' assumptions, research and external sources, as is common in fire modelling work, frequently conducted in each teams' practice.

The teams were given all the details available up to ignition of the fire and a general overview related to the aftermath. This included: the geometry and dimensions of the flat; a detailed and measured layout of the room furniture; 50 photographs of the whole compartment final set-up, windows, fuel packages and instrumentation; and individual descriptions, material, dimensions and photographs of each furniture item. A replica of the sofa and the wastepaper basket were tested under laboratory conditions, and the initial heat release rate of the ensemble was measured in the furniture calorimeter. This calorimeter experiment was allowed to burn until one third of the sofa mass was consumed and then the fire was then

\footnotetext{
¥ In order to avoid bias in the predictions from The University of Edinburgh team, the modellers were kept apart from the experimentalists and submitted their input file before the actual test was conducted.
} 
extinguished. This heat release rate measurement was also provided to the teams. Information on the ventilation conditions included size, photographs and status of the windows and doors. One of the main compartment window panes was externally forced to break at $800 \mathrm{~s}$ after ignition, and this information was also provided to the teams. Meteorological data from two nearby weather stations was also available. Media coverage was inevitable and thus all teams were provided with copies of selected news articles which included photographs and journalist descriptions of the event as seen from the outside. A 5-min video recorded with a hand-held camera, summarising the event, the compartment before and after the fire, and the fire development as seen from outside the building was also provided to the teams as part of the round-robin set of data. It is important to note that the extent of this information by far exceeds the typical set of data available for a user when attempting to simulate a fire of this nature.

\subsection{Input and Output Files for the Simulations}

In total, ten simulations were submitted: eight CFD simulations using FDS4 (McGrattan and Forney 2006), and two zone-model simulations using CFAST (Peacock et al. 2000). No limitations or suggestions were given regarding the fire model to be used. Each team was free to choose the model deemed most suitable or preferred for the task. The organisers endeavoured to include as many different models as possible in the round-robin study, but users of other codes declined the invitation to participate or withdrew.

Table 1 summarises the most important assumptions made in each simulation. Each simulation domain is shown in Figure 5. More information and detailed descriptions of each input file are provided by Rein et al. (2007, Chp 10).
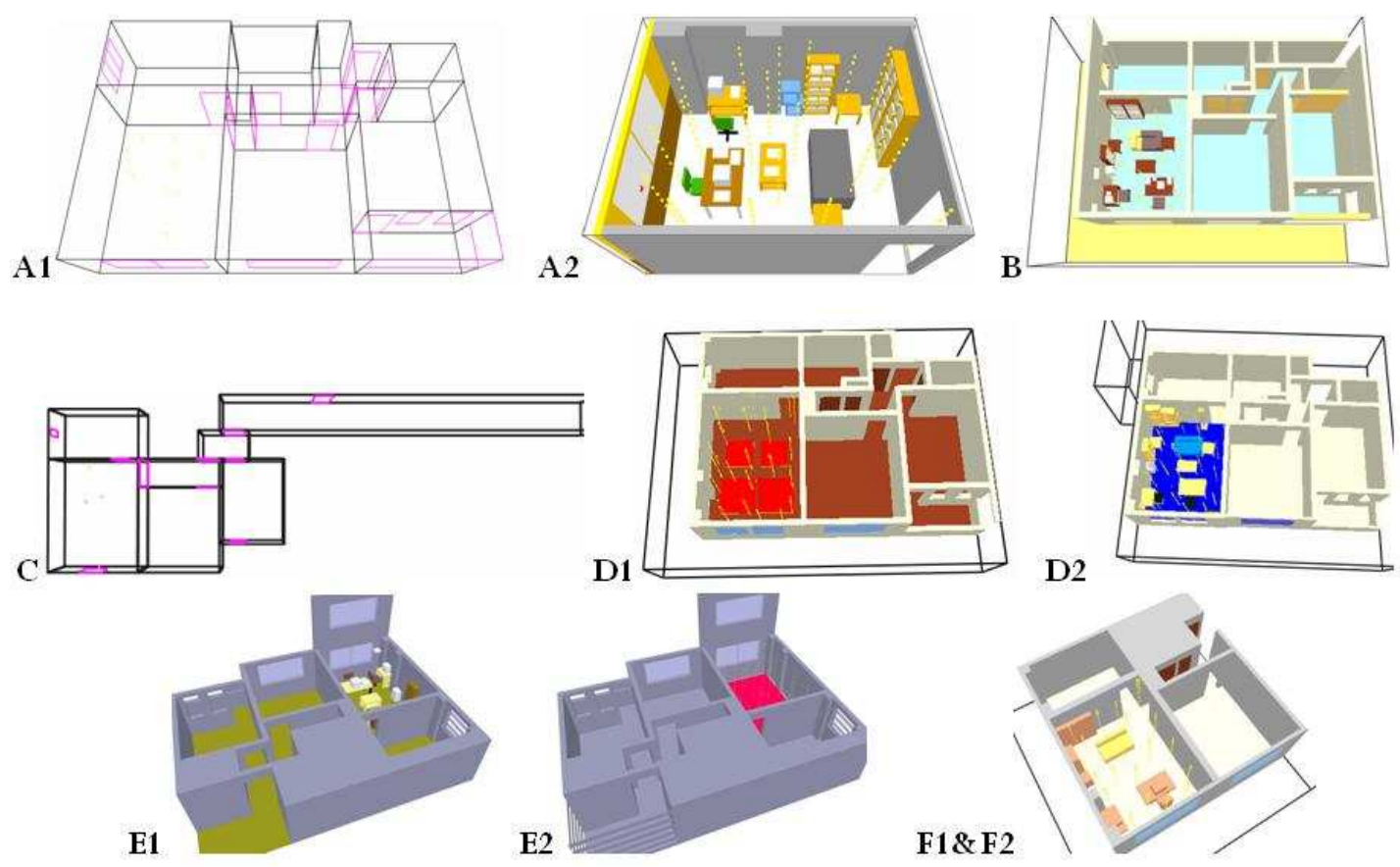

F1\& F2

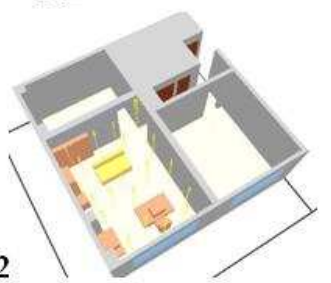

Figure 5: Computational domain for each of the simulations 


\section{Table 1. Summarised information of each simulation's input file. More information and detailed descriptions of each of the input file are provided by Rein et al. (2007, Chp 10).}

\begin{tabular}{|c|c|c|c|c|}
\hline $\operatorname{Sim} \#$ & $\begin{array}{c}\text { Fire } \\
\text { Model }\end{array}$ & $\begin{array}{c}\text { ERT* } \\
{[\mathrm{h}]}\end{array}$ & $\begin{array}{c}\text { Grid } \\
{[\mathrm{mm}]}\end{array}$ & General description of input to the simulation \\
\hline A1 & CFAST & 0.01 & - & $\begin{array}{l}\text { Domain includes the whole flat. HRR is partially prescribed and partially } \\
\text { predicted. Initial fire source prescribed using the HRR from a NIST sofa } \\
\text { experiment. Ignition of secondary items predicted by ignition } \\
\text { temperature and material properties. }\end{array}$ \\
\hline A2 & FDS 4 & 153 & 50 & $\begin{array}{l}\text { Domain includes only the main compartment. HRR is partially prescribed } \\
\text { and partially predicted. Initial fire source prescribed using the HRR from } \\
\text { a NIST sofa experiment. Ignition of secondary items predicted by ignition } \\
\text { temperature, material properties and prescribed surface burning rate. }\end{array}$ \\
\hline B & FDS 4 & 23 & $\begin{array}{l}\text { from } 5 \\
\text { to } 500\end{array}$ & $\begin{array}{l}\text { Domain includes the whole flat. HRR is partially prescribed and partially } \\
\text { predicted. Initial fire source prescribed using the measured HRR from } \\
\text { sofa replica experiment plus the remaining } 2 / 3 \text { sofa mass that was allowed } \\
\text { to burn further. Ignition of secondary items predicted by ignition } \\
\text { temperature, material properties and prescribed heat of vaporization }\end{array}$ \\
\hline $\mathrm{C}$ & CFAST & 0.01 & - & $\begin{array}{l}\text { Domain includes the whole flat and the main floor access corridor. HRR } \\
\text { is partially prescribed and partially predicted. Initial fire source prescribed } \\
\text { using the measured HRR from sofa replica experiment as given. Ignition } \\
\text { of secondary items predicted by ignition temperature and material } \\
\text { properties. }\end{array}$ \\
\hline D1 & FDS 4 & 19 & 100 & $\begin{array}{l}\text { Domain includes the whole flat. HRR is fully prescribed using initially a } \\
\text { uniform t-square fire over the sofa area and then values based on } \\
\text { ventilation conditions. }\end{array}$ \\
\hline D2 & FDS 4 & 128 & $\begin{array}{c}\text { from } 50 \\
\text { to } 100\end{array}$ & $\begin{array}{l}\text { Domain includes the whole flat. HRR is fully predicted. Ignition of } \\
\text { secondary items predicted by material properties and pyrolysis model for } \\
\text { flame spread. }\end{array}$ \\
\hline E1 & FDS 4 & 55 & 100 & $\begin{array}{l}\text { Domain includes the whole flat. HRR is fully predicted except ignition } \\
\text { that is a small wastepaper basket fire. Ignition of secondary items } \\
\text { predicted by ignition temperature and material properties. }\end{array}$ \\
\hline E2 & FDS 4 & 33 & 100 & $\begin{array}{l}\text { Domain includes the whole flat. HRR is fully prescribed using initially a } \\
\text { uniform t-square fire over the sofa area and then values based on } \\
\text { ventilation conditions. }\end{array}$ \\
\hline $\begin{array}{c}\mathrm{F} 1 \& \\
\text { F2 }\end{array}$ & FDS 4 & 170 & 90 & $\begin{array}{l}\text { Domain includes the main compartment, kitchen, bedroom- } 1 \text { and } \\
\text { hallway. HRR is partially prescribed and partially predicted. Initial fire } \\
\text { source prescribed using the measured HRR from sofa replica experiment } \\
\text { but extrapolated with a t-square fire for the remaining } 2 / 3 \text { of sofa mass. } \\
\text { The peak HRR is raised by } 20 \% \text { in F1 and by } 40 \% \text { in F2. Ignition of } \\
\text { secondary items predicted by ignition temperature, material properties } \\
\text { and prescribed surface burning rate. }\end{array}$ \\
\hline
\end{tabular}

\footnotetext{
* Estimated running time on the respective computers used
} 
The teams were asked to provide results in three ascending levels of complexity:

1) General fire behaviour and time to major events (e.g. ignition of nearby objects, flashover, window breakage, burn-out).

2) Transient fire behaviour by zones (e.g. average temperature of different layers and rooms, growth of smoke layer, ignition of other items).

3) Transient fire behaviour by fields, both in space and time (e.g. temperature, flow and species concentration fields). This level suits CFD models only.

The process of converting the data from CFD model-type to zone model-type information and the assumptions inherent to the process were the responsibility of each team and considered as part of the round-robin study. The conversion of the experimental data point measurements to zone-type data was done assuming that the smoke layer interface is located near the $100{ }^{\circ} \mathrm{C}$ isotherm. A sensitivity study for this criterion was conducted and results provided include isotherms in the range from $90^{\circ} \mathrm{C}$ to $250^{\circ} \mathrm{C}$.

\section{Comparison and analysis of the results}

It is important to keep in mind while analysing the results that all simulations were forecasts conducted a priori. In other words, quoting the words attributed to Sir Winston Churchill (circa 1945): "I always avoid prophesying beforehand because it is much better to prophesy after the event has already taken place".

The large pool of data submitted by the round-robin participants greatly exceeds what can be presented in this paper. Thus, only a selection of the most important results is presented and depicted in Figures 6 to 14.

\subsection{General fire behaviour}

The predicted results for the maximum average temperature in the compartment together with the time to reach flashover (and experimental values for comparison) are summarised in Table 2. The predicted times to flashover varied approximately between a $180 \%$ overprediction down to a $100 \%$ under-prediction and fell into two main groups, those predicted at $800 \pm 80 \mathrm{~s}$ ( $\sim 13 \mathrm{~min})$ - very close to the time for forced window breakage at $800 \mathrm{~s}-$ and those that predicted flashover before $180 \mathrm{~s} \pm 80 \mathrm{~s}(\sim 3 \mathrm{~min})$. One simulation predicted that no flashover would occur. Similarly, the predicted maximum average temperatures in the compartment varied approximately between a $50 \%$ over-prediction down to a $70 \%$ underprediction. 


\section{Table 2: Comparison of simulated time to flashover and maximum average temperature in the smoke layer of the main compartment with experimental data.}

\begin{tabular}{|c|cc|}
\hline Simulation & $\begin{array}{c}\text { Time to } \\
\text { Flashover[s] }\end{array}$ & $\begin{array}{c}\text { Maximum Average Smoke } \\
\text { Layer Temperature }\left[{ }^{\circ} \mathrm{C}\right]\end{array}$ \\
\hline A1 & 850 & 790 \\
A2 & 290 & 500 \\
B & 840 & 690 \\
C & no flashover & 200 \\
D1 & 200 & 720 \\
D2 & 80 & 1150 \\
E1 & 180 & 900 \\
E2 & 180 & 610 \\
F1 & 720 & 590 \\
F2 & 850 & 720 \\
\hline Experimental & $\mathbf{3 0 0}$ & $\mathbf{7 5 0}$ \\
\hline
\end{tabular}

\subsection{The global heat release rate}

The global heat release rate (HRR) is given in Figure 6. The same legend is used for the results in all the subsequent figures (continuous line for CFD models, dashed line for zone models, and dotted for the experimental data). Three distinct stages are observed: initial growth, first post flashover stage until compartment window breakage, and subsequent second post-flashover stage. The heat release rate inside the main compartment was calculated during the test using the principle of oxygen depletion. The inflow of air and outflow of combustion products at the openings of the compartment were established by means of temperature and gas velocity probe measurements. It was assumed that nearly all the oxygen was depleted inside the compartment. The estimated experimental error associated with this calculation is presented in Figure 6, based on a conservative overestimation of the two main sources of error. The total airflow into the compartment was measured using only three probes per vent and results in an upper bound of $53 \%$ difference between the inflow and outflow values during the first stage post-flashover and a $13 \%$ difference during the second stage. Relaxation of the complete oxygen depletion assumption provides a lower bound estimate of the HRR error of $18 \%$ if the oxygen concentration in the compartment were $4 \%$ in volume. The HRR measurements convey an approximately steady $3 \mathrm{MW}$ fire between the onset of flashover (at $300 \mathrm{~s}$ ) and the compartment window breakage at $800 \mathrm{~s}$. Thereafter the HRR is circa $5 \mathrm{MW}$ until forced extinction, as shown in Figure 6. These HRR measurements are in good agreement with simple hand-calculations using ventilation factors. These calculations and details of the HRR measurement technique can be found in reference (Abecassis-Empis et al. 2008, Rein et al. 2007 (Chp 3)).

The simulations show a wide scatter of predicted fire behaviours. One simulation (D2) over-predicts the HRR by $100 \%$, another (E1) provides a reasonably good prediction and all other simulations under-predicted the HRR in the range of $30 \%$ to $90 \%$. Note that two simulations (F1 and F2) compare poorly to the measurements but only in time, since the HRR values are adequately predicted for the post-flashover stages. Most teams attempted to partially 
predict rather than fully prescribe the heat release rate. Only two models prescribed it completely (D1 and E2). For the two simulations that fully prescribed the HRR (D1 and E2), the prescribed values are not reached in the model due to unburnt fuel leaving the domain via the vents. It is worth noting that all except one (D2) of the simulations predicting flashover before $3 \mathrm{~min}$ did not use the measured HRR for the replica sofa. Other teams deemed the measured sofa HRR to be deficient or too slow for the fire growth stage. The best average results and lowest scatter are obtained after the forced window breakage (at $800 \mathrm{~s}$ ), as the teams were informed of the timing of this event.

The HRR curve is the single most important and comprehensive characteristic of fire development, resulting from the time evolution and coupling of many important fire mechanisms. The wide range of simulated HRR curves demonstrates the difficulty in accurately predicting the fire growth in the case of a non-trivial, realistic fire scenario.

\subsection{Zone results}

The results for the hot layer are shown in Figures 7 and 8. Figure 7 shows the evolution of the average hot layer temperature (Fig. 7a) and the hot layer height (Fig. 7b). The experimental values are averaged over the entire layer assuming that during the growth phase the interface is at the $100{ }^{\circ} \mathrm{C}$ isotherm or at the height of the largest temperature gradient when below $100{ }^{\circ} \mathrm{C}$ at the very beginning of the test. The sensitivity of the height to the smoke layer to variations of the assumed isotherm value is also presented in Figure 7 for the range from $90^{\circ} \mathrm{C}$ to $250^{\circ} \mathrm{C}$. The experimentally calculated smoke layer temperatures were insensitive (less than $3 \%$ change) to variations in smoke layer height criteria within the same range. The smoke height calculations agree with visual estimates of the smoke layer height, during the fire growth stage, obtained from the camera footage (Abecassis-Empis et al. 2008, Rein et al. 2007 (Chp 3)). During the post-flashover stages, the video cameras confirm that the smoke layer engulfed the whole compartment and thus the height to the smoke layer is zero.

There is a wide scatter of modelling results shown in both figures. Most simulations underpredicted the hot layer temperature. Four simulations fell within a $10 \%$ to $40 \%$ underprediction range and the others were above the 50\% range of over- and under-predictions. The very wide range of behaviours predicted reflects the influence of the user's assumptions when converting field results to zone results, as well as the difference in overall assumptions used for the input. It is worth highlighting that the simulation that performed the best at predicting the HRR (E1), predicting it within a $10 \%$ range, predicted the average hot layer temperature within a $30 \%$ range but differs greatly from the experimental measurements of smoke layer height.

Figure 8 shows the extinction coefficient of the smoke layer. The experimental error for these measurements is estimated at $10 \%$ on average, based on the comparison of laser measurements of the extinction coefficient and hand-calculations using the visual recordings from cameras (Abecassis-Empis et al. 2008, Rein et al. 2007 (Chp 3)). There is a wide scatter of predicted values and in this case, the experimental measurements are mid-range between the predictions, and there is no bias towards under- or over-prediction. 


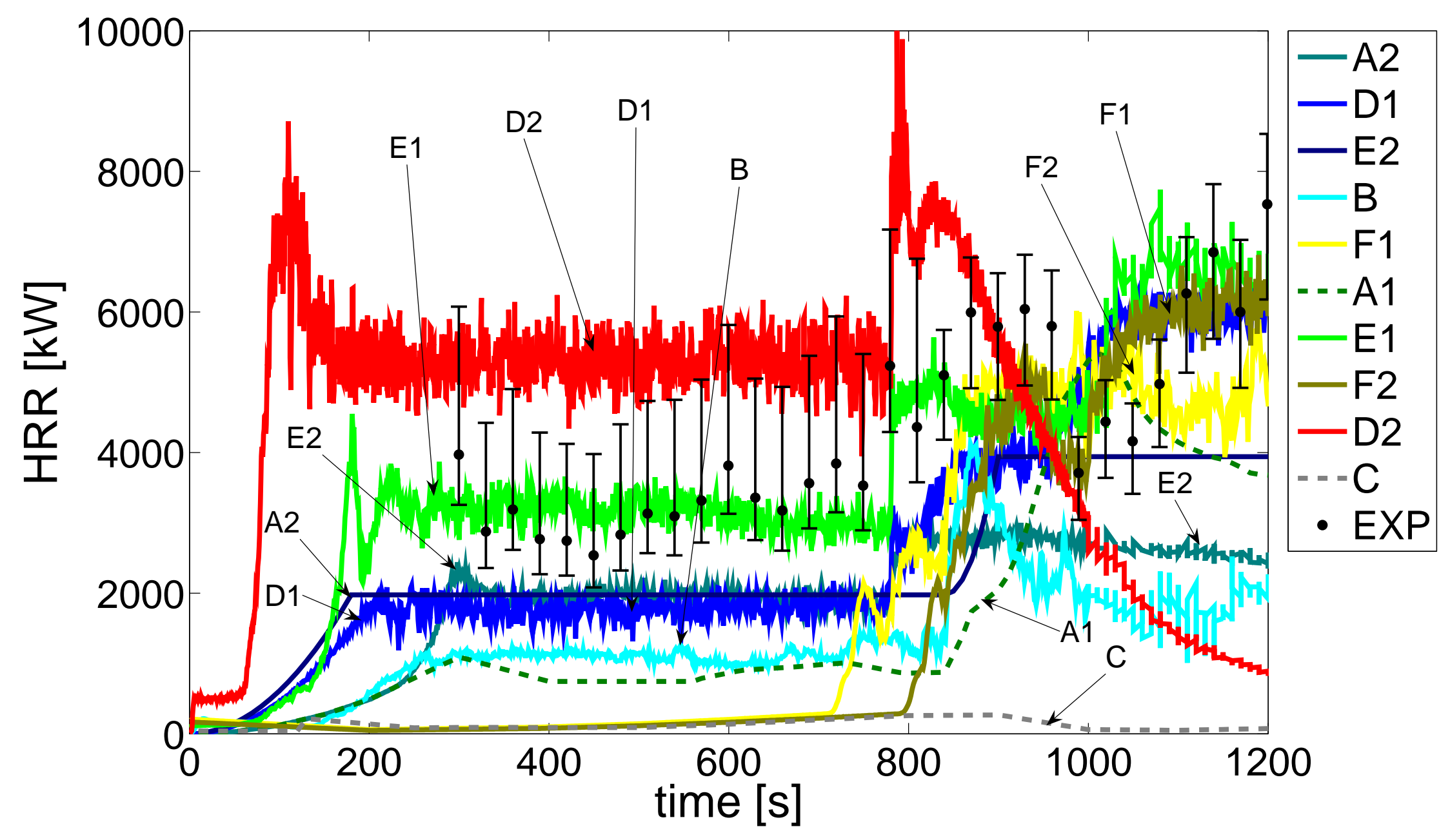

Figure 6: Evolution of the global heat release rate within the compartment. Legend for the different curves: continuous line for CFD simulations; dashed line for zone model simulations; and dotted for the experimental data with error bars. 


\subsection{Field results}

Localised results of field variables are shown in Figures 9 to 14. Figures 9 and 10 show the local gas-phase temperatures, as a function of height, at different times and locations throughout the compartment. Three times are chosen as representative of the three distinct stages: during fire growth (200 s), first stage post-flashover $(700 \mathrm{~s})$, and the second stage post flashover $(1100 \mathrm{~s})$; and two locations are chosen: northeast, near the sofa, and southwest, near the window (see locations marked in Figure 2). The experimental error is plotted with the temperature measurements and calculated to be a maximum of $20^{\circ} \mathrm{C}$ due to small errors in the spatial locations and the radiation correction for the thermocouple readings (AbecassisEmpis et al. 2008, Rein et al. 2007 (Chp 3)). This maximum error is conservatively applied to all thermocouple readings reported in the paper. In general, there is a wide range of predicted temperature results (roughly $\pm 80 \%$ in respect to the experimental measurements) with a bias towards under-prediction. A relatively lower scatter is observed during the second stage of the post-flashover period and also near the window, away from the larger fuel load at the northeast corner. The simulation that predicts the HRR within $10 \%$ (E1) of the experimental measurements, over-predicts local temperatures up to $200 \%$ during the growth phase but post-flashover, the disparity is reduced to an average $25 \%$ difference.

Local results for the instrumented wall, east of the main compartment (see Figure 2), are shown in Figures 11 to 14 . Figures 11 and 12 show the total incident heat-flux ${ }^{4}$ close to the centre of the wall, both at different times and locations. The experimental error from the thinskin calorimeter gauges is estimated by comparison of different smoothing techniques to treat the derivative of the readings and adding the calibration and radiation errors (Amundarain 2007). This way, it is calculated that before flashover the error in heat flux is about $13 \%$ and thereafter about 5\%. In general, the scatter is large, particularly during the growth phase and at lower heights. Predictions are better higher up the wall and during the first post-flashover stage.

Similarly, Figures 13 and 14 show the wall surface temperature at different times and locations approximately at the centreline between the north wall and the kitchen door. The experimental error is shown with the temperature measurements. As with the heat flux, the general scatter is large, especially during the growth phase and at lower heights. However, in general terms, the scatter is higher for the wall temperatures than that of the wall heat-fluxes.

\footnotetext{
${ }^{4}$ Thin-skin calorimeter gauges measure total incident heat flux including convective and radiative contributions.
} 

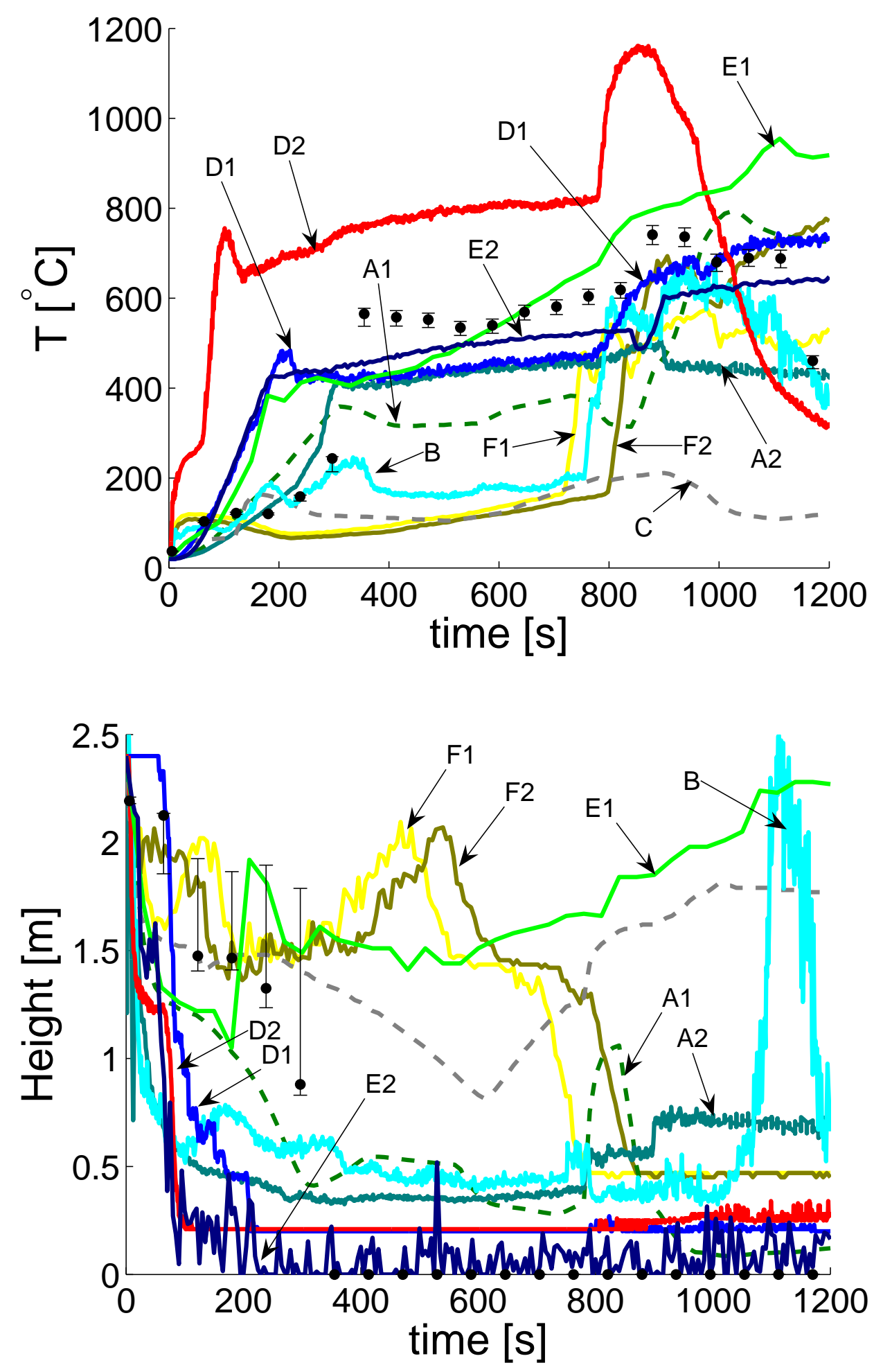

Figure 7: Evolution of the hot layer in the compartment, a) average temperature; and b) height to the interface from compartment floor. Experimental values derived assuming the smoke layer interface at the $100^{\circ} \mathrm{C}$ isotherm. The legend in Figure 6 applies. 


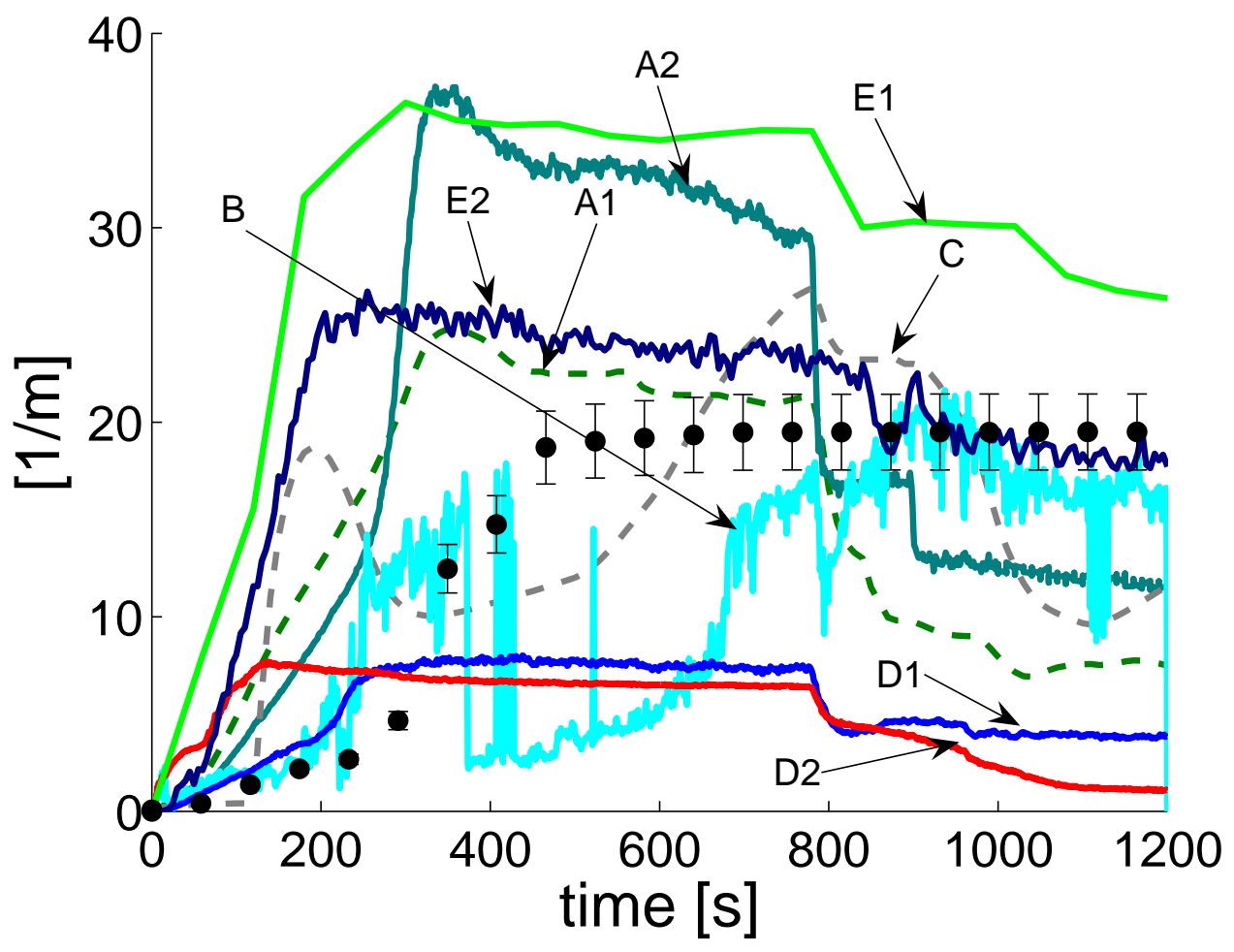

Figure 8: Evolution of the average extinction coefficient in the hot layer and error bars. The legend in Figure 6 applies. 

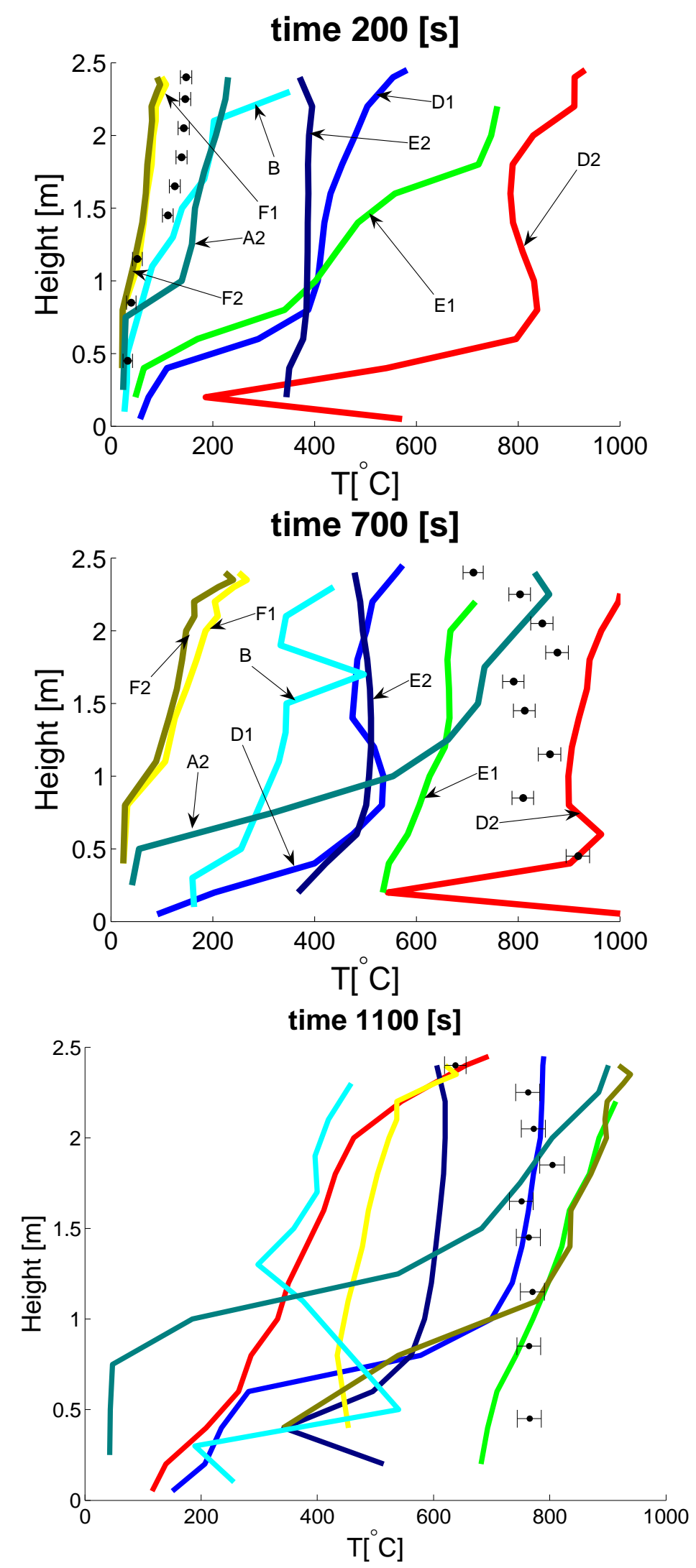

Figure 9: Gas-phase temperature vs. height from the floor in the main compartment at three different times, in the northeast corner near the sofa (see Figure 2). Only CFD simulations and experimental data. The legend in Figure 6 applies. 

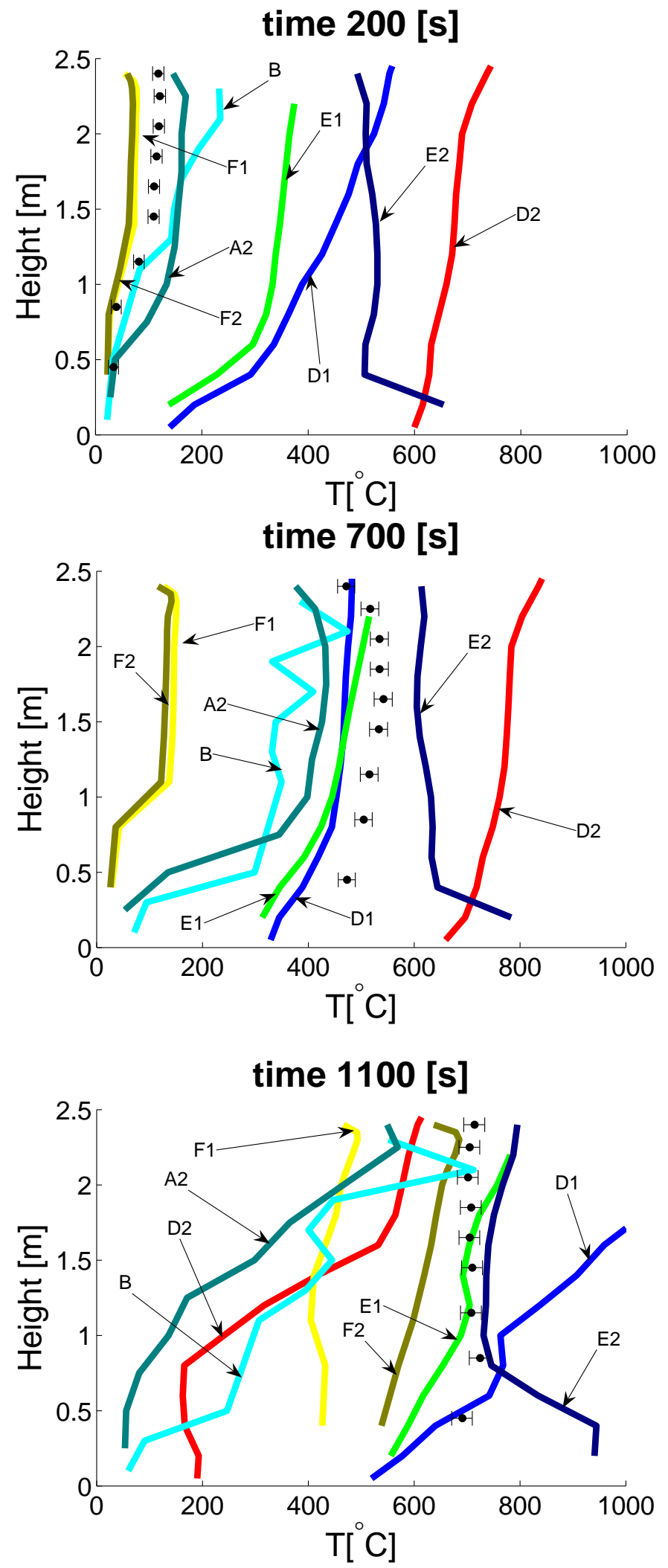

Figure 10: Gas-phase temperature vs. height from the floor in the main compartment at three different times, in the southwest corner near the window (see Figure 2). Only CFD simulations and experimental data.

The legend in Figure 6 applies. 


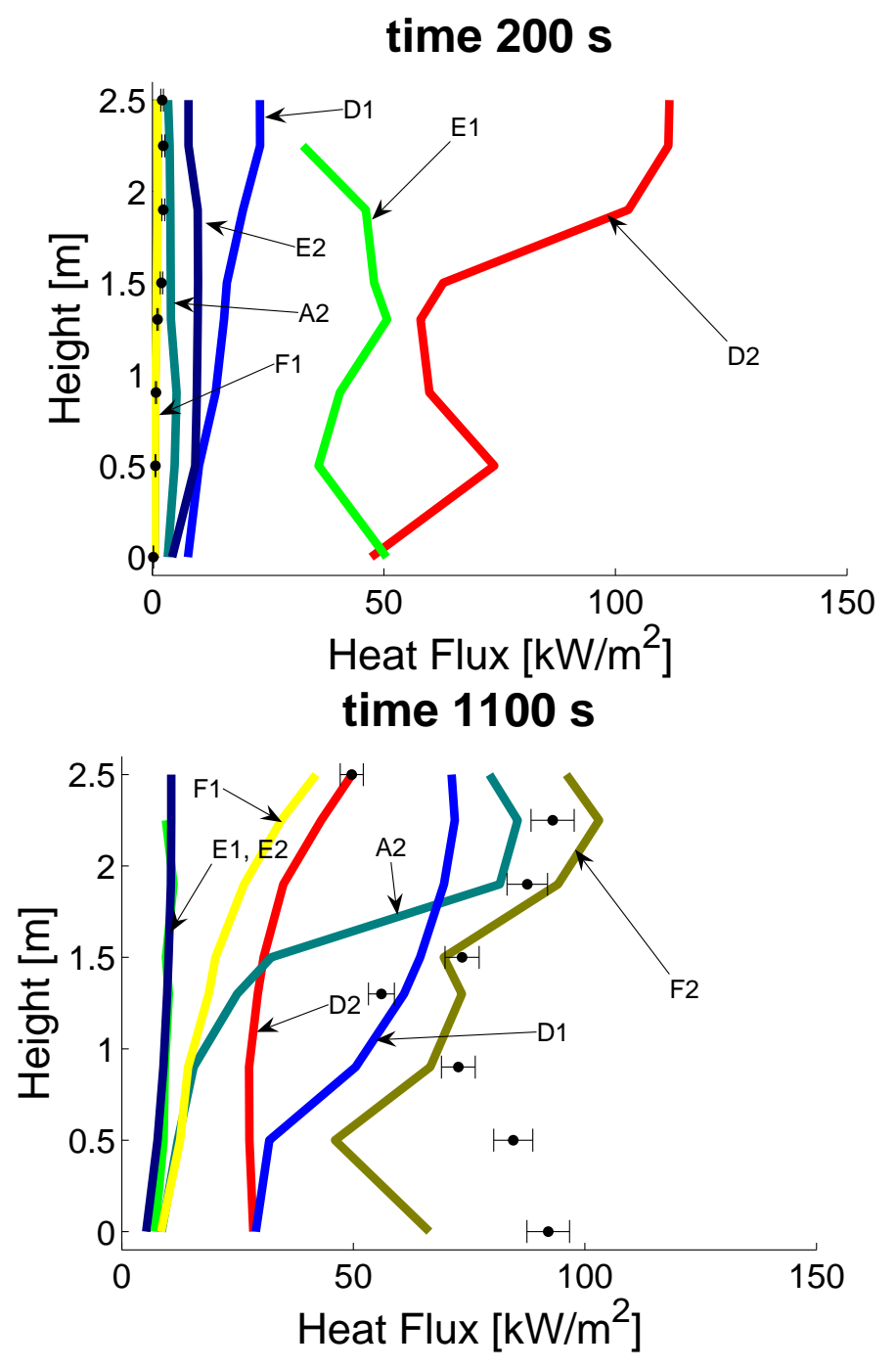

Figure 11: Local total incident heat-flux vs. height on the east wall of the main compartment at three different times. Only CFD simulations and experimental data. The legend in Figure 6 applies. 

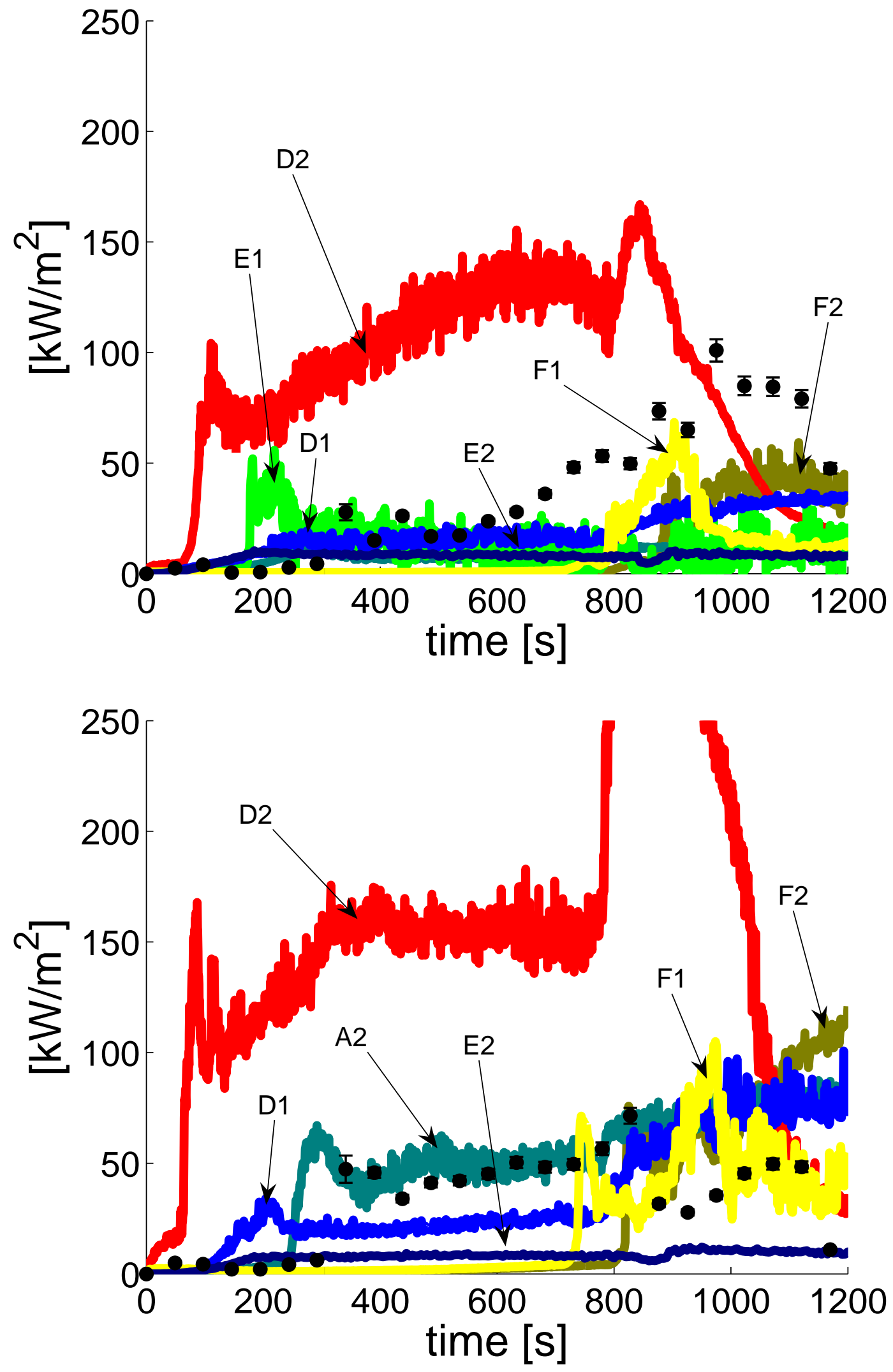

Figure 12: Evolution of the local total incident heat-flux on the east wall of the main compartment, at heights of: a) $250 \mathrm{~cm}$; and b) $50 \mathrm{~cm}$ from the floor. Only CFD simulations and experimental data. The legend in Figure 6 applies. 

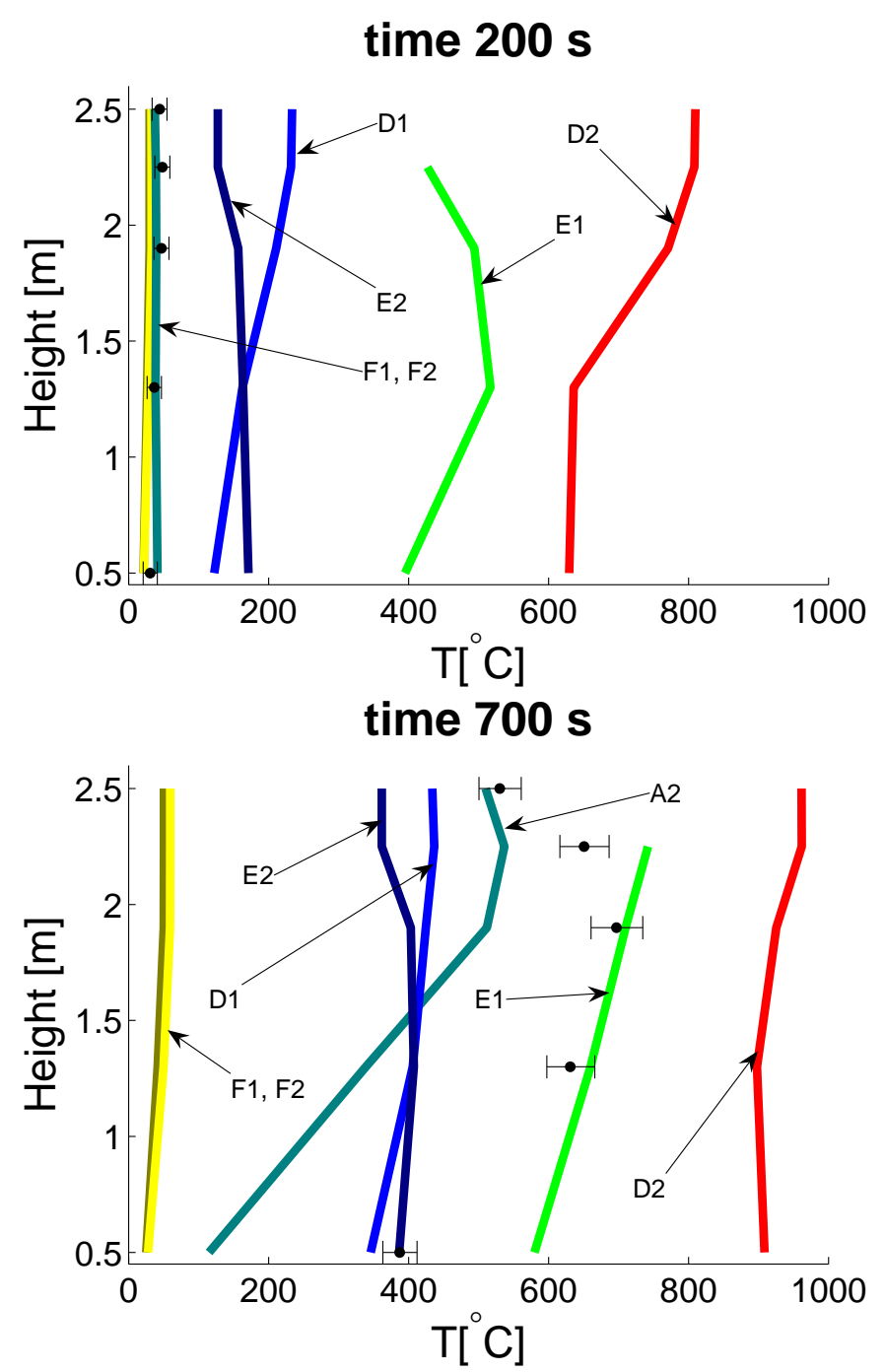

time $1100 \mathrm{~s}$

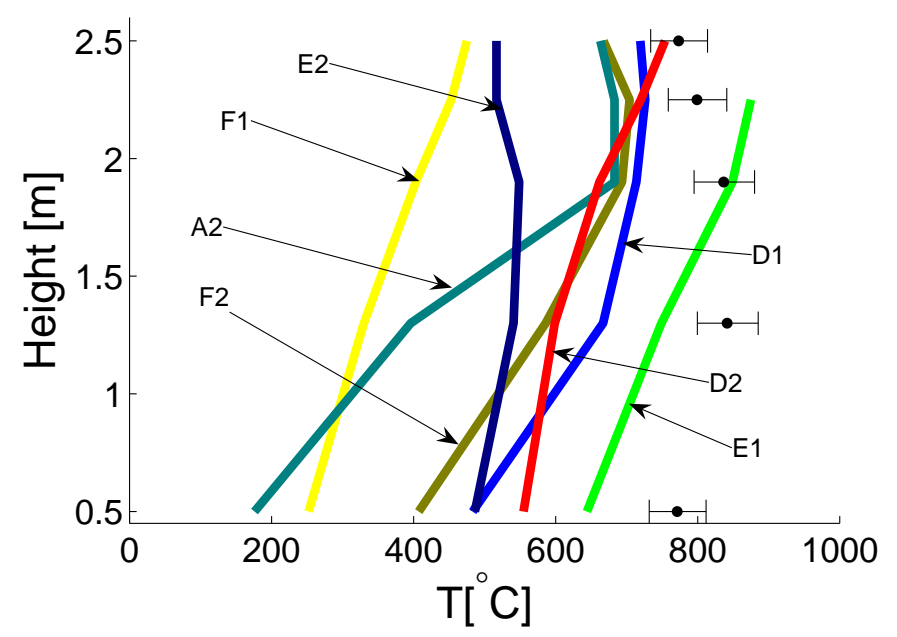

Figure 13: Local surface temperature vs. height on the east wall of the main compartment for three different times. Only CFD simulations and experimental data. The legend in Figure 6 applies. 

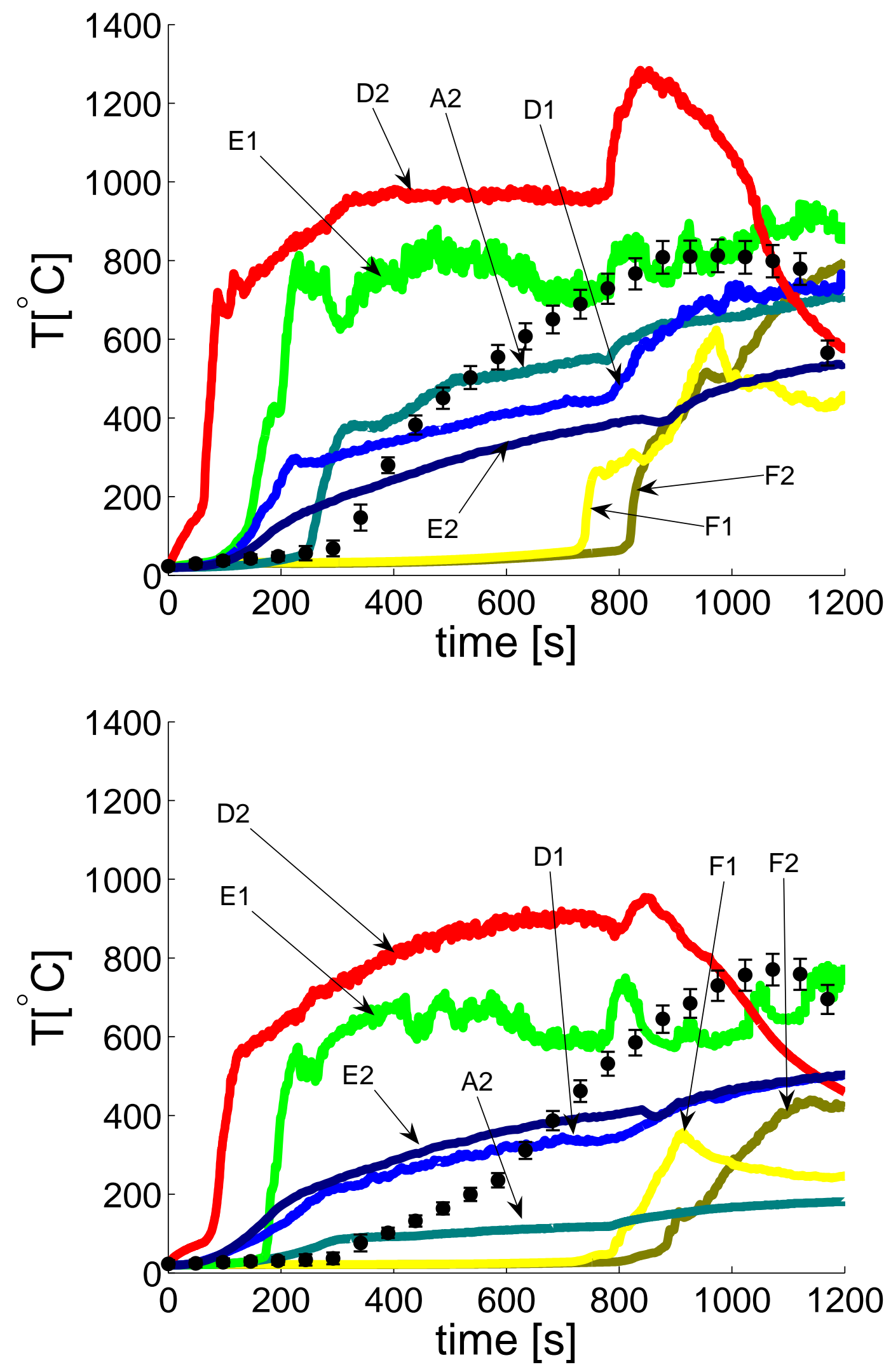

Figure 14: Evolution of the surface local temperature on the east wall of the main compartment, at heights of: a) $250 \mathrm{~cm}$; and b) $50 \mathrm{~cm}$ from the floor. Only CFD simulations and experimental data. The legend in Figure 6 applies. 


\section{Discussion of Results}

The results indicate large scatter and considerable disparity, both amongst the predicted fires and between the predicted fires and the experimental data. The scatter of the simulations is much larger than the estimated experimental error. Moreover, comparison between the range of predicted hot layer temperatures (seen in Figure 7a) and the differences between Test One and Test Two (seen in Figure 4) further demonstrates that the scatter is also much larger than the expected experimental variability.

Although not the intent of the paper, the results show that out of the ten simulations; one provided good results; four provided acceptable results in some sense; and five did poorly. It is important to emphasise that none of the predictions accurately predicted the time to flashover. One simulation predicted HRR development and wall heat fluxes adequately, but diverged from experimental data on other local quantities. Thus, one conclusion is that in complex modelling scenarios, such as Dalmarnock, good results at the global compartment scale do not necessarily correlate to good results at the local scale. For example, it is observed that while a simulation could provide good predictions of the global compartment HRR, it may be simulating wrongly the location and height of the flames or the surface area of the fire, hence failing to predicted local quantities.

The greatest source of scatter originates in the prediction of the fire growth - i.e. the heat release rate. This is due to the inherent complexity in fire growth modelling, particularly for flame spread and ignition of secondary fuel items. Since most participants used the same fire model, FDS4, it is reasonable to think that the wide range of predicted behaviour is mostly the result of the uncertainty associated with the definition of valid input data under the constraints of the model (assumptions and parameter values). The large number of degrees of freedom (i.e. apparent possible assumptions and uncertainty in the parameter values, among others) and the broad variability of the material properties available in the literature lead to large variability in the results. This variability needs to be considered when fire modelling is used to predict fire growth in complex scenarios. These conclusions are expected to be applicable to the full suite of fire models currently available, and not uniquely to the two models used in this study. This is further corroborated in the recent round-robin study (Copalle et al. 2008) conducted using ten different fire models. These results also indicate a significant scatter around the experimental measurements, even when the measured HRR of the fire is provided for direct input.

With the purpose of illustrating the difference between a priori and a posteriori modelling, Dalmarnock Fire Test One has been used in subsequent studies (Rein et al. 2007 Chp 11, Jahn 2008 and Lazaro et al. 2008) to show that it is possible to conduct a posteriori FDS simulations that reproduce the general fire behaviour to a satisfactory level. This was achieved due to the availability of sufficient experimental data of the real behaviour for reference, allowing for an adequate set up of the input file. Nevertheless, achieving simulation results comparable to the experimental data was a very laborious task. Several simulations were required, with repeated comparison to the experimental results and subsequent fine-tuning of input parameters until convergence to an acceptable level of agreement was achieved. 


\section{Concluding Remarks}

A realistic and repeatable fire test was conducted under conditions that are particularly relevant to CFD modelling validation. The study is an assessment of the state-of-the-art of fire modelling in a non-trivial, realistic scenario and evaluates the process of fire modelling as a whole, including the prediction of the heat release rate and the effect of different assumptions, input parameter values, computational approaches and user interactions with the model.

The aim of the round-robin exercise was to forecast the test results as accurately as possible, and not to provide an engineering analysis with conservative assumptions or safety factors. Design for fire safety was not the objective of the exercise. The issue of how to use reliably fire modelling for safety and engineering design is a very important issue currently under research in many institutions and firms.

The Dalmarnock Test involved multiple fuel packages and nontrivial fire growth. The results presented here show that current modelling cannot provide good predictions of HRR evolution (i.e. fire growth) in realistic complex scenarios like Dalmamock. Fire modelling is not yet able to predict the HRR and more research efforts need to be tailored towards this issue. However, fire environments away from the flames could be calculated if an accurate HRR is part of the input data to the modelling process. This is because current modelling tools provide good predictions of the effects of a fire in the far field once the fire growth is known.

Nevertheless, the general behaviour captured by several simulations provides fire features that may be good enough to be applied towards some engineering problems if a robust and conservative methodology is defined. A prerequisite for this methodology is that it can use predictions with crude levels of accuracy and that it applies appropriate safety factors.

\section{Acknowledgements}

Our gratitude to the Building and Fire Research Laboratory at NIST for developing the computer fire models used in this study and for making them freely available. We regret that users of different fire models withdrew from the study or declined our invitation to participate.

Thanks to Chris Lautenberger who provided very constructive reviews of this paper and helped to improve it.

The experiments and the round-robin study would not have been successful without the help of many colleagues at the BRE Centre of Fire Safety Engineering at The University of Edinburgh. Specially, thanks must go to Thomas Steinhaus, Adam Cowlard, Hubert Biteau, Aitor Amundarain, Martin Gillie, Ricky Carvel, Chris Schemel, Dougal Drysdale, Stephen Welch, Ruth Thompson and many others.

The authors are grateful for the funding and the help of the many organisations involved in the Dalmarnock Fire Tests: BBC 'Horizon' programme, Engineering and Physical Sciences Research Council, The University of Edinburgh, Glasgow Housing Authority, Strathclyde Fire 
\& Rescue Service, Glasgow Caledonian University, Lion TV, BRE Trust, Xtralis, Powerwall Systems and the EU Programme Alban. This work has formed part of FireGrid www.firegrid.org - and was co-funded by the UK Government Strategy Board's Collaborative Research and Development programme.

\section{References}

Abecassis-Empis, C., P. Reszka, T. Steinhaus, A. Cowlard, H. Biteau, S. Welch, G. Rein, J.L. Torero, Characterisation of Dalmarnock Fire Test One, Experimental Thermal and Fluid Science $32(7$,$) \quad pp. 1334-1343, 2008. Accessible at$ http://www.era.lib.ed.ac.uk/handle/1842/2513

Amundarain, A., Assessment of the thermal efficiency, structure and fire resistance of lightweight building systems for optimized design, PhD Thesis, University of Edinburgh, 2007. http://hdl.handle.net/1842/2128

ASTM E1355, Standard Guide for Evaluating Predictive Capability of Deterministic Fire Models, American Society for Testing and Materials, West Conshohoken, PA, 2005.

Beard, A.N., On a priori, blind and open comparisons between theory and experiment, Fire Safety Journal 35, pp. 63-66, 2000.

Beard, A.N., Problems with Using Models for Fire Safety, chapter 14 of The Handbook of Tunnel Fire Safety, edited by A.N. Beard \& R. Carvel, London, Thomas Telford, 2005.

Copalle, A., P. Van Hulle, D. Joyeux, L. Bustamante, E. Guillaume, D. Marquis, A. Thiry, M. Suzanne, L. Gay, P. Lamuth, C. Rome, A. Muller, P. Fromy, F. Demouge, P. Breton, S. Suard, S. Melis, A simulations exercise for CFD and zone models in the case of a bedroom fire, $9^{\text {th }}$ International Symposium on Fire Safety Science, Work-in-Progress Poster, Karlsruhe, Sept 2008.

Cox, G., Turbulent closure and the modelling of re by using computational fluid dynamics, Philosophical Transactions of the Royal Society A 356 (1748), 1998, pp. 2835-2854.

Cox, G., S. Kumar, Modeling Enclosure Fires Using CFD, Chapter 3-8 in SFPE Handbook of Fire Protection Engineering, 3rd Edition, 2002.

Barlow, R.S., J.H. Frank, A.N. Karpetis, J.Y. Chen, Piloted Methane/Air Jet Flames: Scalar Structure and Transport Effects, Combustion and Flame 143, pp. 433-449, 2005.

Cox, G., R .Chitty, S. Kumar, Fire Modelling and the King's Cross Fire Investigation, Fire Safety Journal 15 (1), 1989, pp. 103-106.

Emmons, H.W., Fire Research Abroad, Fire Research Abstracts and Reviews 10 (2), 1968, pp. 133-143.

Emmons, H.W., The Prediction of Fires in Buildings, Proceedings of the Combustion Institute 17, 1978. 
Hakkarainen T., O. Keski-Rahkonen, L. Lindberg, CIB W14 Round Robin of Code Assessment: Design Report of Scenario C, VTT Technical Research Centre of Finland, 1999.

Jahn, W., G. Rein, J.L. Torero, The Effect of Model Parameters on the Simulation of Fire Dynamics, Fire Safety Science 9, pp. 1341-1352, 2008. doi:10.3801/IAFSS.FSS.9-1341. Accessible at: http://www.era.lib.ed.ac.uk/handle/1842/2696

McGrattan, K.B., Fire Modeling: Where Are We? Where Are We Going?, Fire Safety Science 8, 2005, pp. 53-68. doi:10.3801/IAFSS.FSS.8-53

McGrattan, K.B., G. Forney, Fire Dynamics Simulator (Version 4) User's Guide, NIST Special Publication 1019, National Institute of Standards and Technology, Gaithersburg, MD, USA, 2006.

Miles, S.D., S. Kumar, G. Cox, Comparisons of blind predictions of a CFD model with experimental data, Fire Safety Science 6, 2000, pp. 543-554. doi:10.3801 /IAFSS.FSS.6-543

Milke, J., Kodur, V., Marrioon, C., 2002, A overview of fire protection in buildings, FEMA 403 - World Trade Center Building Performance Study, Appendix A.

Lazaro, M., H. Boehmer, D. Alvear, J.A. Capote, A. Trouve, Numerical Simulation of Fire Growth, Transition to Flashover, and Post-Flashover Dynamics in the Dalmarnock Fire Test, Fire Safety Science 9, pp. 1377-1388, 2008. doi:10.3801/IAFSS.FSS.9-1377

Novozhilov, V., Computational Fluid Dynamics Modeling of Compartment Fires, Progress in Energy and Combustion Science 27 (6), 2001, pp. 611-666.

NUREG-1824 and EPRI 1011999, Verification and Validation of Selected Fire Models for Nuclear Power Plant Applications, Vols. 1-7, U.S. Nuclear Regulatory Commission, Washington, DC and Electric Power Research Institute, Palo Alto, CA, 2007.

Peacock, R.D., P.A. Reneke, W.W. Jones, R.W. Bukowski, G. Forney, A User's Guide for FAST: Engineering Tools for Estimating Fire Growth and Smoke Transport, National Institute of Standards and Technology, Special Publication 921, 2000.

Pitts, W.M., Murthy A.V., deRis J.L., Filtz J.R., Nygard K., Smith D., Wetterlund I., Round Robin Study of Total Heat Flux Gauge Calibration at Fire Laboratories, Fire Safety Journal 41 (6), pp. 459-475, 2006.

Pope, N., C. Bailey, Quantitative comparison of FDS and parametric fire curves with postflashover compartment fire test data, Fire Safety Journal 41 (2), pp. 99-110, 2006.

Rein, G., C. Abecassis-Empis \& R. Carvel (Editors), The Dalmarnock Fire Tests: Experiments and Modelling, The University of Edinburgh, ISBN 978-0-9557497-0-4, November 2007. Accessible at http: / /www.era.lib.ed.ac.uk/handle/1842/2037

Reneke P.A., Peatross M.J., Jones W.W., Beyler C.L., Richards R., A Comparison of CFAST Predictions to USCG Real-Scale Fire Tests, Journal of Fire Protection Engineering 11 (1), pp. 43-68, 2001. 
Salley M.H., Dreisbach J., Hill K., Kassawara R., Najafi B., Joglar F., Hamins A., McGrattan K.B., Peacock R., Gautier B., Verification and Validation--How to Determine the Accuracy of Fire Models, Fire Protection Engineering Magazine, Spring 2007.

Wen J., Kang K., Donchev T., Karwatzki J., Validation of FDS for the prediction of mediumscale pool fires, Fire Safety Journal 42 (2), 2007, pp. 127-138.

Rein, Torero, Jahn et al.

Round-Robin Study of a priori Modelling Predictions of The Dalmarnock Fire Test One, Fire Safety Journal 44 (4), pp. 590-602, 2009 doi: $10.1016 /$ i.firesaf.2008.12.008

Copy available at http://www.era.lib.ed.ac.uk/handle/1842/1152 